\title{
A Corpus-Based Multimodal Approach to the Translation of Restaurant Menus
}

\author{
Saihong Li, University of Stirling
}

Abstract: Translated restaurant menus facilitate tourism and consumerism, but menu translation remains a peripheral area of professional translation and Translation Studies. This has economic consequences, because translations that exclude a dish's ingredients, cooking methods, or cultural associations may deter consumers. This article analyses translated menus featuring Chinese dishes in order to establish the extent to which intersemiotic, image-based approaches are used to complement written translations; the level of consistency with which ingredients and cooking methods are translated; the frequency of culturally-specific dish names that are challenging to translate. Corpus-based methodology is used to compare 3000 Chinese dish names and their translations from China, Taiwan, and abroad. The data reveals very limited intersemiotic translation in existing menus, inconsistent translations of ingredients and cooking methods, and a high percentage of dishes with culturally-specific names. However, these are often omitted in translation, or lack supplementary information concerning their ingredients. It is proposed that a multimodal translation approach incorporating Jakobson's tripartite theory can enhance menu translation. Menus featuring Pinyin as an intralingual translation can engage learners of Chinese who use this method; interlingual explicitation clarifies a dish's ingredients, cooking methods, and cultural specificity; and intersemiotic, image-based translation conveys culinary artistry more clearly.

Keywords: Food label translation, multimodal analysis, restaurant menus, corpus-based, advertising texts, intersemiotic translation.

\section{Introduction}

The increased interest in gastronomy in today's cosmopolitan society has led to a growing demand for the translation of cookery books, food-related TV series, films, tourist leaflets and gastronomic experiences, food labels, and restaurant menus. However, translation scholars, according to Chiaro and Rossato, 'have so far tended to neglect, ignore or overlook the conceptual connections and familiarities between food and language in different societies and cultures' (2015, pp. 241-245). They further claim, justifiably, that academia, political administrations, and mainstream society focus on 
food production, consumption, costs, and waste, and on their concomitant economic, legal, and medical consequences, rather than on translation-related issues.

Restaurant menus and their translations are hybrid texts, informative and also operative with an advertising function. As well as providing information about a dish's composition and preparation, their purpose is 'to appeal to the expected addressee [...] to represent and advertise a restaurant and to play an important role in the tourist business' (Ruzaite, 2006, p. 259). Food Studies, a discipline whose influence has increased in recent decades (Albala, 2013), has inspired translators to discuss the interlinking concepts of food, culture, and translation. This interest culminated in two international conferences on 'Food and Culture in Translation' in Italy in 2014 and 2016. Conference papers focusing on the translation of European food and culture were published in The Translator in 2015 , the first collection of food-related translation articles to be published in a translation journal. It emphasized the importance of translation 'in a huge transcultural cooking pot' and the necessity of tackling 'the "grey zone" of food translation' (Chiaro and Rossato, 2015, p. 238). Another perspective was provided by De Marco who analysed the evocative, culturally specific qualities of New Zealand dish names and ingredients in New Zealand English and Maori (2015, p. 311). Drawing on Cohen and Avieli (2004), she suggested that menu translations often adopt a culinary ethnoclassification that is designed to be user-friendly for tourists by using transliterated or translated names of local dishes and ingredients, supplementing these names with photos as a form of intersemiotic translation.

Semiotica (July 2016) featured a special issue on 'Semiotics of Food' which was another significant collection of food-related translation articles. Its guest editor, Simona Stano, discussed food and identity in the context of sushi, arguing that the adaptation of sushi to suit local tastes in Canada and America illustrates how Japanese ethnic cuisine has been influenced by food glocalisation (2016, pp. 81-104); this therefore results in numerous Western variations of sushi. My article builds on several elements that emerge in Stano's discussion of the translation and transformation of sushi, and in De Marco's study of the food sections of guidebooks to New Zealand and their translation into Italian. This found that the linguistic and cultural specificity of New Zealand's food-related terminology was sometimes translated incompletely or inappropriately (De Marco, 2015, p. 324). When De Marco's study is analysed in conjunction with other work such as Fuentes-Luque's investigation of the quality of menu translation in southern Spain (2012), a discernible hypothesis that requires exploration is 
that global tourism's increasingly frequent encounters with culturally specific local dishes are not being matched by an increasing accuracy in the accompanying menu translations.

With regard to China's translation traditions, for centuries scholars primarily dedicated themselves to literary translation. However, the 2008 Olympic Games in Beijing and the 2010 Expo in Shanghai awakened a realization among Chinese scholars that the supposedly 'marginal' area of menu translation was as important as more mainstream fields within Translation Studies. Today, CNKI (China National Knowledge Infrastructure), China's largest academic digital resource, has recorded over 147 articles on menu-related translation; however, these constitute less than $1 \%$ of the overall number of publications in Translation Studies in China (Xiong 2013). Scholarly work referenced in the CNKI on restaurant menu translation in China can be summarised into two categories: 1) error analysis; 2) the evaluation of individual translation strategies / principles in practice. Research on error analysis suggests that literal translation, transliteration, free translation, and mixed translation strategies are frequently used to translate Chinese gastronomy. This is exemplified by Huang's study (2007), in which he identifies typical word-for-word translation mistakes found in menu translation, and the reliance of restaurateurs on homemade, improvised translations rather than engaging professional translators. He recommends a government-level standardization of menu and dish name translation. In his doctoral thesis, Xiong (2013) argues that the translation of restaurant dishes is a cross-cultural communication act and an advertising activity with economic impact. Thus, literal translations of metaphorical Chinese dish names do not help the target language receptors to understand a menu, and the communicative function is not achieved.

As the above examples imply, Chinese and Western scholarship on menu translation seldom interact. For example, the special issues of The Translator in 2015 and Semiotica in 2016 did not reference research conducted in other, non-Western environments, and included very limited language pairs. Similarly, Chinese scholarship habitually excludes Western input concerning food-related translation. In addition, the above-mentioned studies often limit themselves to discussing specific translation error types rather than developing an overarching theoretical framework to facilitate menu translation. Surprisingly, as Fuentes-Luque (2016) observes, menu translation has remained a peripheral area of professional translation and thus 'not worthy of analysis' and/or academic attention. Therefore, in commercial contexts, menu translation is 'neglected by both restaurant owners and managers and tourism authorities' (pp. 2-10). The economic impact of this is considerable, since consumers may receive menus on which the ingredients of dishes are unclear, the cooking 
methods are not articulated, a dish's fascinating cultural associations are missing, and on which inadequate literal translations of dish names may appear.

The purpose of this article is twofold: to identify the strategies used in the translation of Chinese dishes from Chinese into English by using three parallel corpora that contain over 3000 names of Chinese specialities and their translations, the material having been collected from China, Taiwan, and also from Chinese restaurants located outside Asia; to assess the efficacy of the existing translation strategies and then address the problems and weaknesses that are identified both by this research and in other work by scholars such as De Marco. Without being unduly prescriptive in its conclusions, this article's delineation of practical frameworks to enhance the quality of menu translation is an attempt to move beyond the descriptive approaches that sometimes characterize research within Translation Studies and towards the criterion of real world impact which necessarily underpins contemporary academic scholarship. This article advocates the systematic incorporation of multimodality into menu translation, and the use of intralingual, interlingual, and intersemiotic translations that integrate words and images to achieve greater communicative clarity.

\section{The Parallel Corpora}

Within Translation Studies, parallel corpora can be used for 'a range of comparative purposes and may increase our knowledge of language-specific, typological and cultural differences, as well as of universal features' (McEnery and Xiao, 2007, p. 1). This particular use of corpora is well suited to the first phase of research outlined in this article, the identification of the principal strategies used in translating Chinese dishes within China itself, Taiwan, and also beyond Asia. In carrying out this research, I have collected data for food label translation corpora over the past seven years, and the corpus is still expanding. This article's data comprises three versions of restaurant menu translations (Table 1). Version 1 contains official Chinese state-approved translations (hereafter T1) and features two sources, the first being Enjoy Culinary Delights: A Chinese Menu in English (美食译苑一中文菜单 英文译法) which was published for the Olympics in 2008. It contained 2,862 Chinese menus and dishes in English, and constituted the first government-sponsored attempt to standardise Chinese restaurant menu translation. The second source, Xuhuiqu Chinese Menu in English (徐汇区餐饮服务 行业中文菜单英文译法), was published for Expo 2010, and mainly features Shanghai dishes in English translation. Version 2 (hereafter T2, featuring 2882 dishes) is formed of data from Taiwan, including menus and dishes from restaurants, Chinese Menus in English (中菜英譯對照表) ${ }^{1}$ and 
One Hundred Popular Taiwanese Dishes (百大小吃隻語菜) ${ }^{2}$. Version 3 (hereafter T3) contains 2987 dishes and is a collection of Chinese menus and dishes found in restaurants outside Asia, mainly in the West.

The Chinese scholars involved in the state-approved project to standardize the translation of dish names established a framework of reference for their work. They identified seven key gastronomic elements such as cooking methods, ingredients, and appearance (listed in Table 2 below) that could be used as components for translating Chinese dish names. Their rationale was that translations based on these elements would facilitate a foreign consumer's understanding of what a given speciality comprised (Zhao, 2010, pp. 1-3). Although these seven elements formed a framework for a China-based translation project - involving dishes whose translations form corpus T1 in this article - they are equally relevant to the translation of Chinese dish names in Taiwan and beyond Asia. Therefore, I identified a list of key words (such as the cooking methods listed in Table 4) related to each of the seven gastronomic elements, and these words were searched for within the dish names contained in T1, T2, and T3. Sketch Engine and Microsoft Excel were used to collect and retrieve data from the sources mentioned above. Sketch Engine - an online platform for corpus management and query tool for language data and corpora analysis - was chosen as it visualises language data and supports parallel corpora both in English and Chinese. In order to create my own corpora on the platform, the collected data was converted into separate columns in Excel to create aligned, side by side segments. The statistics were calculated via Sketch Engine by searching each of the three corpora and recording every instance of key words linked to the seven key gastronomic elements in Chinese dish names. The effectiveness and appropriacy of the translations of key words linked to the seven elements are analysed in Examples One, Two, and Three below.

The translations in T1 naturally prioritized concrete details such as a dish's ingredients and flavours, and similar outcomes were found for T2 and T3. The data shows that many dishes were translated with more than one element, such as 炒面 whose translation, 'Stir-Fried Noodles with Vegetables', outlines its cooking method and ingredients. Although these translations, based on seven key gastronomic elements of dishes, conveyed many useful concrete, itemized details, their major flaw was their rigid application both to factual/informative dish names (dishes may be named after their ingredients, cooking methods and/or their origins) and also to poetic/artistic dish names which evoke historical events, metaphorical expressions, and anecdotes. Example Three (below) outlines the 
consequences of this. Consequently, different dishes were translated into the same restricted format in English, e.g. 乡巴佬炒䲞片 (Sichuang cuisine) and 清炒鲴糊 (Zhejiang cuisine) were both rendered as 'sautéed shredded eel'.

A translation brief for menu translation would arguably centre on the transmission of key information including ingredients and cooking processes, but also on conveying a dish's culturally evocative origins to increase its fascination for a menu's target readers of foreign visitors to the Far East (T1 and T2) or the residents of Western countries who enjoy the Asian cuisine available locally (T3). The results of comparing the translation approaches used across the three corpora suggest a reliance on the limited options of literal translation, free translation, transliteration, and combinations of these three methods to convey the semantic specificity contained in Chinese dish names. These approaches on their own are not flexible enough to fulfil the requirements of this particular translation brief. For example, literal, word-for-word strategies convey ingredients and cooking methods, but as indicated by several micro-level examples below, cultural references are often omitted or remain in a decontextualized and confusing form. Free translation strategies frequently privilege the cultural or mythical connotations of dishes but their poetic licence causes a lack of clarity; a dish's ingredients and cooking methods often risk omission through this approach.

The implications of using these particular translation strategies require further illustration by means of several corpus examples that focus on the attempted translations of specific elements of dish names: the wide variety of Chinese cooking methods; the specialized cooking technique of hóng shāo, often used for meat dishes; and the culturally specific or poetic names that distinguish many dishes.

\section{Example One: The Translations of Chinese Cooking Methods}

Chinese food culture centres on unique cooking techniques, great diversity, and on a nutritional balance of Yin and Yang. ${ }^{3}$ Preparing Chinese dishes involves several steps which are called 烹调. 'Pēng' means 'to cook'; 'tiáo' means 'to add flavour'. For example, dishes can be boiled first and then stir fried, with seasoning added to finish. Statistics from the largest Chinese search engine BAIDU ${ }^{4}$ indicate that there are over 10,000 Chinese dishes and over 50 different cooking methods and cutting skills, not all of which have English equivalents on the evidence of the 25 different ways of cooking listed in the Oxford Advanced Learners' Online Dictionary. ${ }^{5}$ This mismatch between the languages exacerbated by the fact that English and Chinese are unrelated languages - complicates food label 
and restaurant menu translation and poses a challenge for translators. Although translation can become 'an act of reclaiming or recentering the identity, a reterritorialization operation' (Brisset, 2012, p. 346), the examples below indicate that this does not result in transferring all Chinese cooking and cutting methods into English.

The corpus data shows that several Chinese cooking methods have been accurately translated into specific Western equivalents such as frying, steaming, braising, stewing, boiling, and roasting (Table 3). But by contrast, the data also shows that ten different cooking methods in T1, 扒 / 烩 / 红烧 / 扣 / 炖 / 烧 / 煀 / 烧 / 爆 / 滑 have been all translated as 'braise'. 'Sauté' and 'stew' have also been used for translating many different Chinese cooking methods, such as 回锅 / 煸 / 炒 / 爆 / 溜 / 扒 / 炝 / 滑 / 卷 / 烧, although there are differences between any two of these methods and the dish may consequently taste completely different. It is worth noting, however, that different translation strategies have been used for the translated menus collected in the corpora; this means that not all translations include cooking methods. The frequency of these cooking methods can be seen from Table 3 and Table 4. T2 and T3 have similar problems to T1 in terms of using the same English word to translate different Chinese cooking methods. The data implies that there are different levels of translation inconsistency across the corpora. In the official Chinese translation data (T1), 'sauté', 'braise', 'fry', 'steam', and 'stew' as cooking methods are identified as the five most frequently used translations, being used more than 411 times, 308 times, 256, 163, and 136 times respectively. In T2, the Taiwan-based menus and translations, the five most frequent cooking method translations are 'braise', 'fry', 'stew', 'steam', and 'barbecue'. In T3, 'Stir-fried' and 'stewed' were used more frequently, but this may be because these methods are renowned in the West. It is clear that considerable translation loss is occurring from Chinese to English, exemplified in T1 by the high frequency of the term 'sauté' to translate a wide range of Chinese terms ranging from 回锅 to 烧.

\section{Example Two: Translations of Hóng Shāo}

Inconsistencies and errors also occur in translating the same term in the context of dishes that feature a specific cooking style or ingredient. For example, hóng shāo appears at least 40 times in each corpus, with very few accompanying images (see Table 5); this is a cooking process used for meats such as pork (but also fish and vegetables), which have condiments and sauces added in the later stages of the dish's preparation. A search for hóng shāo in the names of different dishes resulted in a range of different translations. In T1, the same term 红 烧 was translated differently as 'braised', 'sautéed', 
and 'stewed', sometimes with brown sauce, sometimes with soy sauce, and sometimes without sauce in the examples. Examples from T3 in Table 3 indicate that 红 烧 was translated into two ways of cooking as 'stewed' and 'braised'. 红 烧, in examples from T2, was rendered as 'simmer' and 'braise'. 红烧肉 was translated as 'soy-braised meat', which is a preferred translation that captures the dish's essential ingredients and cooking methods. Clearly, 'simmer' is a translation error in the final example. The examples indicate that the same Chinese term appeared to be interpreted and translated differently across the corpora, with some apparently random translation choices for this term in all three renditions. Again, the lack of pictures to accompany the dishes deprives consumers of a clear image of the specialities on the menu.

\section{Example Three: The Translation of Poetic, Culturally Specific Names}

The names of most products, or in the context of this article, dishes, normally have an informative function to identify them distinctively and to differentiate them from others. The terminology used in restaurant menus which feature names of Chinese dishes is sometimes mythical and poetic, conveying unique historico-cultural references. This is a distinctive feature of Chinese dish names, and in the minds of many Western consumers there may be an immediate link between these specialities and China's millennial cultural traditions.

Naming strategies can be broadly divided into two types: poetic, culturally specific names, and factual names. Names from the former category evoke legends, historical events, classic literature, and imaginary metaphorical names. For example, the original Chinese version of 'shrimps and egg soup', (金玉满堂), literally means 'gold and jade fill the house'; 'gold' is used metaphorically to convey the colour of shrimps, and 'jade' reflects the colour of egg white. Together, gold and jade represent wealth, a notion originating from the classic philosophical text Dao-Te-Ching. Factual names normally refer to the contents or ingredients used for dishes, although Western naming strategies also sometimes name specialities after places (e.g. Yorkshire pudding, cotoletta alla milanese). The data in Table 6 shows that almost 50\% of Chinese dish names examined in the corpora have poetic, culturally specific names rather than factual names. If these dishes are to be translated effectively, the translations ideally need to convey distinctive cultural references while also fulfilling an informative function by communicating the features and ingredients of the speciality itself. 
The following cases instantiate the different existing strategies used to translate three selected dishes that have an evocative, culturally specific name in Chinese.

\section{Case 1: 全家福}

T1: Stewed Assorted Delicacies

T2: Assorted Dish with Brown Sauce

T3: Combination of shrimps, pork, beef, chicken and mixed vegetables in brown sauce / Happy Family (Jumbo shrimp, fresh scallop, sliced flank steak, pork, chicken, broccoli, red bell pepper and straw mushrooms in garlic sauce)

For Case 1, 全家福 (Happy Family) is a name indicating the traditional Chinese expression of good wishes for family happiness and harmony. T1 translates the cooking method but offers negligible information about the dish's ingredients, namely shrimps, pork, beef, chicken, and mixed vegetables with brown sauce. In addition, it suffers from a loss of implied meaning, of family members living happily together. $\mathrm{T} 2$ rewrites the name as a dish with sauce, although the composition of the dish and sauce are unclear. In T3, The Sunshine Oriental Restaurant in New Hampshire (U.S.) ended up with a lengthy translated name which nevertheless retains the dish's cultural connotation as well as indicating its ingredients.

\section{Case 2: 麻婆豆腐}

T1: Mapo Tofu (Sautéed Tofu in Hot and Spicy Sauce)

T2: Ma-Po Tofu (Ground pork and chunks of tofu in spicy bean paste)

T3: Ma Po Tofu

This well-known Sichuan dish typifies another culturally specific name type, referencing the dish's inventor - a woman with a pockmarked face, Chen Liushi, who invented it in 1862 during the Qing Dynasty. A search online can find over 70 bizarre translations of this dish's name. T1 is a generally valid translation that preserves a reference to the originator's name (although it is unclear whether 'Mapo' is a person, place, or object), applying transliteration to obtain the words Mapo and Tofu, and adding notes to indicate the cooking method, ingredients, and taste. T2 indicates the shape of the pork and tofu as well as the flavour and ingredients of its sauce. 'Ma-Po' is written with a hyphen because Taiwan's Romanisation/Pinyin system, a transcription system from Taiwanese Hokkien, differs from China's Pinyin system. T3 merely uses a similar transliteration method for the name, and 
mentions the dish's key ingredient, tofu. Although T1 may form the basis for an effective translation, there are elements of translation loss concerning the dish's cultural associations and the absence of an accompanying image that might provide extra visual clarity.

\section{Case 3: 佛跳墙}

T1: Fo-tiao-qiang--Steamed Abalone with Shark's Fin and Fish Maw in Broth

T2: Buddha Jump Over the Wall/Shark Fin Soup

T3: Buddha's Delight/Buddha Against Wall

The literal translation of the dish 'fó tiào qiáng' in Case 3 is 'the Buddha jumps over the wall'. This is a Fujian dish of steamed abalone with shark's fin and fish maw in broth. The translation refers to a poem which implies that the dish's delicious aroma would make Buddha scale a wall to taste it. T1 rewrites the name, adding its cooking method, 'steamed', and ingredients 'abalone, shark's fin, and fish maw'. Pinyin is included in a modified form ('fu-tiao-qiang') with hyphens and without tones, but the evocative meaning will be lost to all but the most advanced learners of Chinese. T2 provides a literal translation of the poetic name and a reductive summary of its main ingredient and its form as 'soup'. T3 moves towards translation for the dish's distinctive name, but the essential informative function of the translated dish name is compromised in the absence of details clarifying its appearance, ingredients, and flavours.

As discussed above, figurative and culturally specific names are common in Chinese, especially in marketing texts. In culinary contexts such as the preparation and consumption of meals in restaurants, these figurative naming methods often use the characteristics of colour, aroma, flavour, and local culture to attract customers. It is therefore essential that menu translations engage effectively with the source culture of the dish and the target culture of the consumer, whether domestic or international. Translators have the challenge of capturing a dish's evocative cultural origins as well as conveying its ingredients and preparation methods as informatively and attractively as possible. The above cases indicate clear inadequacies in the existing translation methods used to convey dishes contained in the three corpora, thereby compromising the communication of the dishes' ingredients, cooking methods, and cultural associations. These inadequacies also mirror De Marco's conclusions regarding the translations of New Zealand dishes in guidebooks, since these often did not engage with 'the religious or cultural significance of Māori food or with the traditional use of Māori herbs and spices' (2015, p. 324). 
Another significant factor in the way dish names and their translations were presented across the corpora centred on the use of images to supplement the textual information provided by the translations. While photographs are not guaranteed to convey a dish's unique ingredients and cooking methods, their potential to mitigate some of the deficiencies in translation outlined above, and to convey the essence of a dish, is worth further investigation. With regard to the dishes in the three corpora, despite the intricacy of their cooking methods, the specificity of the ingredients, and their unique cultural origins, textual translations were not extensively supplemented by images of the dishes (see Table 1). Only $7.8 \%$ of dishes in T1 featured images; the figure increased to $27.6 \%$ for $\mathrm{T} 2$ and then $\mathbf{2 8 . 8 \%}$ for $\mathrm{T} 3$, but this still entailed a reliance on word-based translations to convey elaborate Chinese specialities, a responsibility that only a minority of the translations fulfilled. The following sections of this article incorporate the use of images into a systematic translation framework to minimize examples of translation loss and to convey the distinctive names of restaurant dishes, their skilled elaboration, and their ingredients, not just in China but worldwide.

\section{A Multimodal Framework for the Translation of Restaurant Menus}

Different aspects of the corpus data discussed in the preceding sections indicate that processes of menu translation need to engage more meaningfully with restaurant customers of all nationalities. In a society now predicated on image-based communication and advertising, it is difficult to justify the succinct word-based translations that populate the three corpora, translations that are inadequate on several levels and which would be of limited use even to foreign consumers with an interest in Chinese culture and language (the likely readers, for example, of the menu translations in T1 (China) and T2 (Taiwan). There is a strong case for moving beyond the written word and implementing a multimodal approach for the translation of restaurant menus. If terminology coined by Kress and Van Leeuven $(2001$, p.4) is applied to the particular context of restaurants, then the design and production of menus need to convey more adeptly the discourse (the socially constructed knowledge of the origins, ingredients, and preparation methods of dishes) of menus to assist a consumer's interpretation of them.

Multimodality emphasizes the combined communicative potential of multi-semiotic systems that encompass written texts and images, and also different types of technology that incorporate visual, verbal, and aural modes. The social function and purpose of meanings can be modified via the simultaneous articulation of different modes. For example, in the binary context of image/text 
relations, different semiotic modes can interlink so that each reinforces or complements the other's meaning; Kress and Van Leeuwen define multimodal texts as 'making meaning in multiple articulations' (2001, p.4). This communicative synergy has beneficial applications for translated texts given their susceptibility to translation loss; in certain contexts, written translations, with their specific characteristics such as font and typeface, could be supplemented by images and their qualities of composition, colour, framing, and distance. To focus momentarily on images, visual resources can be harnessed into a 'grammar of visual design' (Kress and Van Leeuven, 1996: pp. 26465), with a notable semiotic application in terms of producing and communicating meaning in social settings such as restaurants. Ideally, this visual input should not take the form of the large format menus with brash, mass-produced colour images that are placed at restaurant entrances in popular European tourist destinations, the artificiality of which undermines any sense of gastronomic authenticity. Instead, bespoke close-up photographic images that capture the individual colours, forms, and preparation processes of dishes have a potentially valuable function in terms of attracting and informing consumers.

Multimodality in the context of translation research has broadly been interpreted as intersemiotic translation: the communication of verbal signs through non-verbal signs within and across languages and cultures. In terms of Jakobson's categorisation (1959), translation can be seen as a semiotic process, and he argues that translation can occur at intralingual, interlingual, and intersemiotic levels. Besides the notion of intersemiotic translation outlined above, intralingual translation is defined as 'rewording' in the same language code, and interlingual translation is understood as translation proper between different languages. While contemporary scholarship has sometimes attempted to redevelop the categories established by Jakobson, his delineated differentiation of the intralingual, interlingual, and the intersemiotic can still constitute the basis of a practical framework for the translation of restaurant menus, enhancing the meaning-making process and emphasizing the specificity of the ingredients, cooking methods, and cultural origins of dishes.

This article's framework for the translation of restaurant menus draws on the synergy between Kress and Van Leeuwen's multimodality concepts and Jakobson's tripartite theories of translation. Multimodality, for Hodge and Kress (1988, p. 261), is perceived as meanings that 'are constructed through the full range of semiotic forms, through semiotic texts and semiotic practices, in all kinds of human society at all periods of human history'. At this point in human evolution, in a globalized society saturated with images, culturally specific words/texts no longer possess the communicative 
immediacy of pictures. Translation, according to O'Sullivan (2013, p.2), has mainly focused on processing texts from one language into another, and she argues that other semiotic modes, such as images, 'have been all but ignored'. For the purposes of this article, the multimodal meaning-making process is understood as meaning being construed through written verbal signs and visual non-verbal signs as shown in Figure 1. In the context of restaurant menus, words and images can contribute equally to create meaning through diverse media formats. For example, a French restaurant in London, Gastronhome, uses a distinctive combination of modes on its website, including artistic, moving close-up images of its elaborate dishes, and recognizable cognate French terms in its textual content. These two elements and the overall discourse emphasize sophistication, indicating the high quality of the restaurant. As this article proposes in a later section, the concept of using recognizable source language terms together with evocative food images within the target text of a translated menu has a potential cross-cultural application that transcends European contexts.

Translations, as portrayed in Jakobson's categorization (1959/2004, p.233), can occur at an intralingual, interlingual, and intersemiotic level. Intralingual translation, for example, articulates verbal signs by means of other signs from the same language. The concepts within Jakobson's sideby-side tripartite theory have acquired a broader meaning, passing beyond their linear relationship (Toury 1986; Holmes 1988) to a multi-dimensional, multimodal, semiotic process of communication between different linguistic and cultural sign systems (Torresi 2008; Torop 2013). Within a theoretical framework encompassing multimodal approaches to translation as shown in Figure 1, intersemiotic translation based on the visual (images, videos) combined with the written (translated word-based texts) can be used to translate one culture into another with greater clarity. In the context of translating restaurant menus from Chinese into English, there are compelling reasons for including intralingual, interlingual, and intersemiotic translations of the names of dishes originally written in Chinese characters. As regards menus for use in Chinese-speaking territories frequented by Western travellers, besides the initial dish name in Chinese characters, a multimodal approach to menu translation could provide three tiers of translation:

1) Pinyin as intralingual translation. Reflecting Jakobson's notion of intralingual translation, the verbal signs of Chinese characters would be interpreted in an alternative format - Pinyin - to convey their pronunciation. There are valid reasons for this. Firstly, by using the Pinyin format with its Roman letters, the menu reiterates that the dish is authentically Chinese, but its name potentially becomes more recognizable, especially since the names of certain Chinese foods and dishes are 
becoming globally known. An example of this could be the dish 炒面; these characters mean little to most Westerners, but if the Pinyin term 'chăo miàn' is added, this is immediately closer to what is recognizable outside China as 'chow mein'. Many French, Italian, and Spanish restaurants, as exemplified by the Gastronhome restaurant's use of cognate French terms, also feature original dish names on their menus and then add English translations underneath. Chinese menus could therefore use a similar method to maintain and also clarify the identity of dishes through Pinyin. Secondly, according to statistics from Hanban, ${ }^{6}$ there are over 160 million non-native learners of Chinese worldwide, and many Westerners learn Chinese through Pinyin instead of studying Chinese characters at beginners' level. I have personally observed Pinyin being taught in places such as the Chinese Department at the University of Copenhagen. Currently, however, there is a frustrating, unbridged gap for these learners in terms of what they learn and its application in real-life situations in China, since no restaurants or bars use Pinyin on menus. Currently, Pinyin as a form of intralingual translation has been totally neglected in the translation of restaurant menus between English and Chinese, including those analysed in the corpora that underpin this article. Thirdly, if a dish has a culturally specific, artistic name, Pinyin can preserve and transfer its uniqueness, some of which, again, might be understood by travellers with an advanced grasp of Pinyin, and this could be supplemented by further information about the dish's origins.

2) Interlingual translation is the proposed second tier of translation, with the objective of amplifying and rendering more explicit the references to ingredients, cooking methods, flavours, form, and unique cultural origins within the more evocative dish names. Vinay and Darbelnet outlined the concept of explicitation as 'the process of introducing information into the target language which is present only implicitly in the source language, but which can be derived from the context or the situation' $(1995$, p. 8). For the purposes of menu translation using the distinctive translation brief outlined earlier in this article, explicitation as the complex meaning of an individual SL word being distributed over several words in the TL (Pym in Károly and Fóris, 2005) is an appropriate method to convey the nuanced specificity of concepts in the source language menus. Interlingual translation based on explicitation constitutes a necessary component of this article's theoretical basis, because a key, marketable attribute of any dish is its cultural uniqueness, history, and authenticity, which transform it from mere ingredients into a focus of interest for consumers. Translation with explicitation is a strategy to fulfil the essential criterion of conveying the same degree of information as that understood by native consumers of the dish. 
3) The proposed third tier of translation comprises an image of the dish as a form of intersemiotic translation. As the images reproduced in this article show, pictures provide valuable supplementary information to communicate the artistry involved in preparing dishes. While photographs may not automatically enable consumers to deduce which cooking methods have been used, they would illustrate other elements of preparation such as forms of cutting. From a general perspective, images would also help to mitigate text-based translation loss. Aspects of images such as colour and composition take on 'the functions of a mode', and can become 'the carrier of discourses' (Kress and Van Leeuven, 2001, p. 25). In the context of Chinese dishes these elements might elucidate principles such as the presentation of food in an aesthetically attractive way, with contrasting yet complementary ingredients that reflect the prevalent Yin/Yang philosophy. It is the visual, intersemiotic dimension of this article's proposed menu translation format that moves menus beyond a merely informative function towards a more demonstrative advertising function.

\section{The Practical Applications of a Multimodal Translation Approach}

It is appropriate to revisit the preceding sections of this article and apply the proposed multimodal approach to examples of translation characterized by inconsistency, omission, and error.

Example One: The Translations of Chinese Cooking Methods described how translation loss occurred from Chinese to English, exemplified in T1 by the repeated use of the term 'sauté' to translate a wide range of Chinese terms ranging from 回锅 to 烧. Here, the translations would arguably benefit from the use of Pinyin, more detailed interlingual translation, and intersemiotic approaches. The use of Pinyin as an intralingual translation would help travellers to China with a grounding in the language to recognize some of the foods and dishes featured in the TCSL textbooks that they have studied. Interlingual translation using explicitation might suffice to clarify the different cooking procedures involved. If an intersemiotic approach is also used, images could also enable consumers to comprehend the different cooking methods, through the colours and shapes of the dish. However, the corpus data shows that the menus feature a very limited percentage of images: T1 has $7.8 \%$; T2 has $27.6 \%$, and T3 has $28.8 \%$. This indicates that intersemiotic translation approaches have a very limited presence in the corpora, and that innovative formats for menu translation could usefully be developed to provide consumers with multimodal information including images. In a consumerist society predicated on images, it is almost inconceivable that restaurant clients are not provided with images of products that they are going to consume. 
Example Two: Translations of Hóng Shāo outlined through a range of examples how the translations of the cooking method Hóng Shāo were inconsistent and differed widely across the corpora. A multimodal approach incorporating intralingual, interlingual, and intersemiotic translations would give Western customers a better chance of understanding a Hóng Shāo dish's ingredients and preparation. An intralingual use of Pinyin would highlight words like tòufu, now a recognizable globalized commodity, and learners of Chinese would have encountered words like ròu (meat) and hóng (red) early in most textbook-based language courses. A brief, expanded interlingual translation would provide more background detail regarding the application of this cooking method to certain dishes, increasing their distinctiveness and the likelihood of customers selecting them. An intersemiotic image-based translation would help to clarify the distinctive red colour acquired by a dish during this cooking process.

Example Three: The Translation of Poetic, Culturally Specific Names indicated that there were instances of omission in the translation methods used to convey dishes contained in the three corpora, affecting the communication of the dishes' ingredients, cooking methods, and cultural associations. Again, these are weaknesses that a multimodal approach to menu translation could mitigate, and it is a process applicable not just to China but worldwide. For names with evocative, culturally unique origins, as already discussed in the section A Multimodal Framework for the Translation of Restaurant Menus, a multimodal approach can provide three tiers of translation. Intralingual translation into Pinyin will help to engage non-native learners of Chinese who sometimes have extensive vocabularies, but who have not necessarily studied Chinese in the form of characters. An interlingual translation that moves away from the ultra-concise and sometimes inaccurate renderings that have been identified in the corpora, and which instead uses explicitation, would convey more of the cultural specificity of a given speciality. In the commercial context of restaurants this is instrumental in conferring an exotic authenticity upon a dish, connecting it to the consumer's existing awareness of a foreign culture, and incentivizing people to order it. Intersemiotic translation on the menu is desirable, as images are sometimes the only signs that can convey the artistry and techniques with which these dishes are prepared.

The discussion of Case 1, 全家福 (Happy Family), focused on a dish whose name conveys a Chinese expression of good wishes for family happiness and harmony. 
Suggested translation: See Figure 2.7 Quán jiā fú. 'Happy Family': Combination of shrimps, sea food, pork, beef, chicken and mixed vegetables in brown sauce.

Again, an effective translation combination might be: an intralingual rendering in Pinyin to convey the dish's original metaphorical name for the benefit of learners of Chinese (terms such as jiā / family are encountered early in most Chinese language courses); a brief interlingual translation to expand the dish's translation to present its ingredients and cooking methods; and an intersemiotic representation such as a photo to illustrate the varied aspects of the dish's visual appearance that word-based translations would have difficulty in conveying.

It was explained how Case 2, 麻婆豆腐 (Mapo Tofu), is a Qing Dynasty dish whose name referenced its inventor who created it in 1862 . The dish's cultural associations were mainly omitted from the translations collected in the corpora.

Suggested translation: See Figure 3. Mápò dòufu: 'Mápò’s Qing Dynasty Sautéed Tofu in Hot and Spicy Sauce'.

The suggested translation includes a Pinyin rendering of 'dòufu' which may resonate with people who have knowledge of Chinese cuisine, given the global awareness of tofu as an export. An expanded interlingual translation is necessary to transfer both the culinary characteristics of the dish, and, in this case, a carefully selected cultural association using exoticism and compensation. Considering the hybrid nature of menus as texts with an informative/operative-advertising function, there is an argument for omitting a literal translation of 'mápò' as 'a woman with a pockmarked face', but preserving 'mápò' for its exotic resonance and then adding an attractive reference to the Qing Dynasty, given that China's millennial history and culture are well known. This endows the dish with a sense of authentic longevity, enhancing its stature beyond its simple ingredients. An intersemiotic representation of the dish through a photograph also usefully reiterates its wholesome ingredients and appearance.

The initial discussion of Case 3, 佛跳墙 (Buddha Jumps Over the Wall), identified how existing translations were reductive in conveying the dish's ingredients - or omitted them entirely - and sometimes also overlooked the dish's cultural association. 
Suggested translation: See Figure 4. Fó tiào qiáng. 'Buddha Jumps Over the Wall': Steamed Abalone with Shark's Fin and Fish Maw in Broth.

A combination of intralingual translation, interlingual translation through explicitation, and intersemiotic translation would again be effective. As regards the latter, the image used in Figure 4 depicts the dish at its best. A slightly high-angle view of traditional, elegant pots emphasizes the balanced arrangement of the shark's fin, abalone, and vegetables, and the harmonious golden yellow and brown tones of the ingredients, to form a signifier highlighting an attractive combination of Yin and Yang. This is another example of an image (non-verbal) of a dish supplementing the verbal mode in translating or transferring the essence of a speciality to consumers from all cultural backgrounds.

\section{Conclusion}

Menus ideally need to achieve a balance between informing consumers of the ingredients, flavours, and preparation methods of given dishes, and enabling a dish to transcend its physical characteristics by accentuating the cultural uniqueness in its name. The corpus evidence examined in this article suggests that many existing (and official) translations fail to reach this equilibrium. There are inconsistencies in translating individual Chinese terms: for example, 红烧 has been translated differently as 'braised', 'red-cooked', 'sautéed', 'simmered', and 'stewed' across the menus featured in the corpora. On the one hand, there is a tendency to restrict translations of dish names to itemized but unimaginative renderings of ingredients; the corpus data revealed that many poetic or culturally specific names of dishes were omitted from menus, causing detrimental translation loss in an era when a dish's distinctive origins are an attractive selling point. On the other hand, there is also a parallel tendency to focus translations entirely on literal renderings of culturally evocative dish names that offer no indication of a dish's ingredients to foreign consumers. This research has also identified a conspicuous absence of images to clarify and complement a menu's textual translations, a surprising omission given the advertising component and function of menus.

In discussing the challenges posed by advertising texts within Translation Studies, Munday (2004, pp. 204-206) noted that the main solutions that have emerged 'parallel the developments of translation theory over the past forty years' in terms of a 'focus on the target audience, the purpose or skopos of the translation', and the fact that effective advertising texts are 'a clear example of cross-cultural transfer'. The more successful examples of translated restaurant menus reflect these principles, and 
this article has posited that multimodality is an effective vehicle for translations of this type. For example, the target readers envisaged by corpora T1 and T2, namely visitors to China and Taiwan who frequent local restaurants, are likely to have a cultural - and possibly linguistic - interest in these regions. Intralingual translation using Pinyin is a communicative tool that deserves greater consideration, particularly by Chinese restaurateurs and the country's tourist sector as a whole, because Pinyin is a gateway to the Chinese language for millions of learners. Interlingual translation featuring explicitation - and also greater consistency in terminological translation - in order to encompass a dish's ingredients, flavours, and cooking methods, satisfies the target reader's need for clarity regarding what will be consumed. Again, from the perspective of foreign consumers who are one of a translated restaurant menu's target audiences, a richer, more effective, and marketable form of cross-cultural transfer will be achieved by including translations of a dish's distinctive poetic name if it has one. Intersemiotic approaches via images on printed and online menus will enhance the translation of dishes, as images can convey their essence unambiguously. In a purely Chinese context, restaurant menus featuring colour images are now sometimes found in food outlets in major cities, and, as indicated by the preceding analysis of the comparable corpora, it is beneficial to show a greater linguistic, cultural, and visual sensitivity towards the needs of all the receptors of restaurant menus. Associated issues that lie beyond this article's remit and which require analysis include the sociocultural and economic determinants that impact on the work of translators and on translations carried out in the field of food translation, resulting in the inadequate translations that most travellers have encountered. But at a textual level, in the context of menu translation, this article has outlined how interlinked concepts of multimodality constitute a mechanism towards improving the translation of the names and contents of even the most sophisticated and culturally specific dishes.

\section{References}

Albala, K. (2013). Routledge international handbook of food studies. London: Routledge.

Brisset, A. (2012). The search for a native language: Translation and cultural identity. In L. Venuti (Ed.), The translation studies reader (pp. 343-375). London: Routledge.

Chiaro, D., \& Rossato, L. (2015). Food and translation, translation and food. The Translator, 21(3), 237-243. doi:10.1080/13556509.2015.1110934

Cohen, E., \& Avieli, N. (2004). Food in tourism: Attraction and impediment. Annals of Tourism Research, 31 (4), 755-778. doi: 10.1016/j.annals.2004.02.003 
De Marco, A. (2015). Are green-lipped mussels really green? Touring New Zealand food in translation. The Translator, 21(3), 310-326. doi:10.1080/13556509.2015.1103098

Fuentes-Luque, A. (2016). An approach to analysing the quality of menu translations in southern Spain restaurants. Journal of Multilingual and Multicultural Development, 38(2), 1-12. doi: 10.1080/01434632.2016.1187154

Hodge, R., \& Kress, G. (1988). Social semiotics. Oxford: Polity Press.

Holmes, J. S. (1988). Translated! Papers on literary translation and translation studies, Amsterdam: Rodopi.

Huang, F. (2007). On Chinese Menu Translation. Chinese Science and Technology Translators Journal. 20(1), 40-42.

Jakobson, R. (1959)/(2004). On linguistic aspects of translation. In L. Venuti (Ed.), The translation studies reader (2nd ed.) (pp. 138-143). London: Routledge.

Kress, G., \& Van Leeuven, T. (1996). Reading images: The grammar of visual design. London: Routledge.

Kress, G., \& Van Leeuven, T. (2001). Multimodal discourse. London: Arnold.

McEnery, A. M., \& Xiao, Z. (2007). Parallel and comparable corpora: What are they up to? In G. James \& G. Anderman (Eds.), Incorporating corpora: translation and the linguist (pp. 1-13). Clevedon: Multilingual Matters.

Munday, J. (2004). Advertising: Some challenges to translation theory. In B. Adab \& C. Valdes (Eds.), Key debates in the translation of advertising material (pp. 199-220). Manchester: St. Jerome.

O'Sullivan, C. (2013). Multimodality as challenge and resource for translation, Journal of Specialised Translation, 20, 2-14.

Pym, A. (2005). Explaining explicitation. In K. Karoly and Á. Fóris (Eds.), New trends in translation studies. In honour of Kinga Klaudy (pp. 29-34). Budapest: Akadémia Kiadó.

Ruzaite, J. (2006). Text typology in translation. A case study of menu translations. Darbai ir Dienos, $45,257-271$.

Stano, S. (2016). Lost in translation: Food, identity and otherness. Semiotica, 211, 81-104. doi: https://doi.org/10.1515/sem-2016-0100

Torop, P. (2013). The ideological aspect of intersemiotic translation and montage. Sign Systems Studies, 41 (2/3), 241-265. doi: http://dx.doi.org/10.12697/SSS.2013.41.2-3.07

Torresi, I. (2011). Advertising. In M. Baker \& G. Saldanha (Eds.), Routledge encyclopedia of translation studies ( $2^{\text {nd }}$ ed.), (pp. 6-10). London: Routledge.

Toury, G. (1986). Translation: A cultural-semiotic perspective. In T. Sebeok \& P. Bouissac (Eds.), Dictionary of semiotics (pp. 1111-1124). Berlin: Monton de Gruyter. 
Vinay, J.P., \& Darbelnet, J. (1995). Comparative stylistics of French and English: A methodology for translation. (J.C. Sager \& M.-J. Hamel, Trans.). Amsterdam and Philadelphia: John Benjamins.

Xiong, X. (2013). On the C-E translation of the names of Chinese. Shanghai: Shanghai International Studies University.

Zhao, H. (2010). Enjoy culinary delights: A Chinese menu in English. Beijing: Beijing Tourism Publishing.

Table 1 Statistics from the comparable corpora

\begin{tabular}{|l|l|l|l|}
\hline & T1 & T2 & T3 \\
\hline Numbers of images & 243 & 798 & 859 \\
\hline Percentage of images & $7.8 \%$ & $27.6 \%$ & $28.8 \%$ \\
\hline Numbers of dish names & 3101 & 2882 & 2987 \\
\hline
\end{tabular}

Table 2 Seven gastronomic elements identified for the translation of dishes

\begin{tabular}{|l|l|l|l|}
\hline & Corpus T1 & Corpus T2 & Corpus T3 \\
\hline Cooking methods & $51.65 \%$ & $43.35 \%$ & $55.44 \%$ \\
\hline Ingredients & $83.48 \%$ & $80.25 \%$ & $86.13 \%$ \\
\hline Appearance & $4.81 \%$ & $3.10 \%$ & $6.51 \%$ \\
\hline Flavours & $48.82 \%$ & $22.01 \%$ & $59.35 \%$ \\
\hline Name of the dish's creator & $0.77 \%$ & $2.01 \%$ & $1.56 \%$ \\
\hline Geographical origin & $1.78 \%$ & $14.16 \%$ & $1.78 \%$ \\
\hline Pinyin/Transliteration & $9.69 \%$ & $0.12 \%$ & $3.23 \%$ \\
\hline
\end{tabular}

Table 3 Cooking methods and their translation 'equivalents'

\begin{tabular}{|c|c|c|c|c|c|c|c|}
\hline $\begin{array}{l}\text { Cooking } \\
\text { methods }\end{array}$ & $\mathrm{T} 1$ & $\mathrm{~T} 2$ & T3 & $\begin{array}{l}\text { Cooking } \\
\text { methods }\end{array}$ & $\mathrm{T} 1$ & T2 & T3 \\
\hline sauté & $\begin{array}{l}\text { 回锅/煸/炒/爆 } \\
\text { /溜/扒/炝/滑/ } \\
\text { 卷/烧/酱/红烧 }\end{array}$ & $\begin{array}{l}\text { 炒/煎扒/ } \\
\text { 炝/滑/卷/ } \\
\text { 烧/酱 }\end{array}$ & 酱/炒 & braise & $\begin{array}{l}\text { 扒/烩/红烧/扣/ } \\
\text { 炖/烧/埆/烧/爆 } \\
\text { /滑/干烧 }\end{array}$ & $\begin{array}{l}\text { 鑲/燴/ } \\
\text { 釀/紅燒 } \\
\text { /燜/扣/ } \\
\text { 鳌 }\end{array}$ & $\begin{array}{l}\text { 烩/烧/ } \\
\text { 炖 / 红 } \\
\text { 烧/爆/ } \\
\text { 焖 }\end{array}$ \\
\hline $\begin{array}{l}\text { (soft/quick/ } \\
\text { deep/pan } \\
\text { /stir) fry }\end{array}$ & $\begin{array}{l}\text { 煎/滑/爆/干煸 } \\
\text { /贴/酿/卷 }\end{array}$ & $\begin{array}{l}\text { 炒/炸滑 / } \\
\text { 爆 }\end{array}$ & $\begin{array}{l}\text { 炒 / 爆 } \\
\text { / 酥 / } \\
\text { 炸 / 煸 } \\
\text { /滑 }\end{array}$ & stew & $\begin{array}{l}\text { 焖/烧/砂 锅/者 } \\
\text { /锅仔/堡/滑/酿 } \\
\text { /煨/红烧 }\end{array}$ & $\begin{array}{l}\text { 紅燒/清 } \\
\text { 燉/煨 }\end{array}$ & $\begin{array}{l}\text { 烧/扣/ } \\
\text { 炮 / 叉 } \\
\text { 烧/炖 }\end{array}$ \\
\hline steam & 清蒸/蒸/焗 & 蒸/清蒸 & 扣/蒸 & grill & 扒/石烹/烤/烧 & 烤/炭烤 & 烤 \\
\hline boil & 沾水/清炖/煮 & 水煮 & 白/涮 & scramble & 炒/熘 & 炒 & 炒/熘 \\
\hline $\begin{array}{l}\text { barbecue } \\
\text { (BBQ) }\end{array}$ & 碳烧/叉烧 & & 叉烧 & roast & 烤/烧 & 烤 & 烤 \\
\hline bake & 焗/烤/烧/贴 & 烤 & 烧 & crispy & 脆/酥/煎 & 酥 & 酥 \\
\hline marinated & 腌/卤/扣/拌 & 湞 & 腌/卤 & smoke & 熏/醃熏 & 煙燻 & 腊/熏 \\
\hline
\end{tabular}




\begin{tabular}{|l|l|l|l|l|l|l|l|}
\hline sizzling & 铁板 & 铁板 & & griddle & 干锅 & & \\
\hline poach & 白灼/煮 & & & toast & 吐司 & & \\
\hline
\end{tabular}

Table 4 Major cooking methods: numbers of occurrence

\begin{tabular}{|l|l|l|l|l|l|l|l|}
\hline Cooking methods & \multicolumn{3}{|l|}{ Numbers of occurrence } & Cooking methods & \multicolumn{2}{l|}{ Numbers of occurrence } \\
\hline & $\mathrm{T} 1$ & $\mathrm{~T} 2$ & $\mathrm{~T} 3$ & & $\mathrm{~T} 1$ & $\mathrm{~T} 2$ & $\mathrm{~T}$ \\
\hline sauté & 411 & 40 & 350 & braise & 308 & 245 & 271 \\
\hline $\begin{array}{l}\text { (soft/quick/ } \\
\text { deep/pan/stir) fry }\end{array}$ & 256 & 220 & 315 & steam & 163 & 164 & 170 \\
\hline stew & 136 & 30 & 143 & grill & 36 & 15 & 41 \\
\hline boil & 38 & 26 & 20 & scramble & 14 & 13 & 2 \\
\hline barbecue (BBQ) & 21 & 29 & 10 & roast & 42 & 44 & 46 \\
\hline bake & 41 & 36 & 7 & pickled & 36 & 16 & 26 \\
\hline marinated & 35 & 28 & 21 & smoke & 13 & 8 & 3 \\
\hline sizzling & 16 & 12 & 0 & griddle & 11 & 7 & 0 \\
\hline poach & 13 & 10 & 15 & toast & 8 & 32 & 20 \\
\hline
\end{tabular}

Table 5 Translations of 'hóng shāo'

\begin{tabular}{|c|c|c|c|}
\hline & T1 & $\mathrm{T} 2$ & T3 \\
\hline $\begin{array}{l}\text { Numbers of } \\
\text { occurrence }\end{array}$ & 62 & 42 & 41 \\
\hline $\begin{array}{l}\text { Numbers of } \\
\text { images }\end{array}$ & 2 & 4 & 3 \\
\hline \multirow[t]{4}{*}{ Selected examples } & $\begin{array}{l}\text { 百叶红烧肉 } \\
\text { Stewed Pork Cubes and Tofu Skin in } \\
\text { Brown Sauce }\end{array}$ & $\begin{array}{l}\text { 紅燒肉 } \\
\text { Soy-Braised Meat }\end{array}$ & $\begin{array}{l}\text { 红烧肉 } \\
\text { Stewed Pork with } \\
\text { Brown sauce }\end{array}$ \\
\hline & $\begin{array}{l}\text { 红烧鲍片 } \\
\text { Braised Sliced Abalone with Soy Sauce }\end{array}$ & $\begin{array}{l}\text { 紅燒划水 } \\
\text { Braised Fish Tail in Brown } \\
\text { Sauce }\end{array}$ & $\begin{array}{l}\text { 栗子红烧肉 } \\
\text { Braised Pork with } \\
\text { Chestnuts }\end{array}$ \\
\hline & $\begin{array}{l}\text { 什菌炒红烧肉 } \\
\text { Sautéed Pork in Brown sauce with } \\
\text { Assorted Mushrooms }\end{array}$ & $\begin{array}{l}\text { 紅燒海參燴川丸子 } \\
\text { Stewed Sea Cucumber with } \\
\text { Meat Balls }\end{array}$ & $\begin{array}{l}\text { 红烧茄子 } \\
\text { Braised Aubergine }\end{array}$ \\
\hline & $\begin{array}{l}\text { 红烧狮子头 } \\
\text { Braised Pork Ball (sic) in Brown Sauce }\end{array}$ & $\begin{array}{l}\text { 紅燒烤麩 } \\
\text { Simmer Baked Bran (sic) }\end{array}$ & $\begin{array}{l}\text { 红烧狮子头 } \\
\text { Stewed Pork Balls }\end{array}$ \\
\hline
\end{tabular}

Table 6 Percentage of poetic, culturally specific names and factual names in the corpora

\begin{tabular}{|l|r|r|r|}
\hline & \multicolumn{1}{|l|}{ T1 } & \multicolumn{2}{l|}{ T2 } \\
\hline Poetic, culturally specific names & $49.30 \%$ & $34 \%$ & $59.60 \%$ \\
\hline Factual names & $50.70 \%$ & $66 \%$ & $40.40 \%$ \\
\hline
\end{tabular}




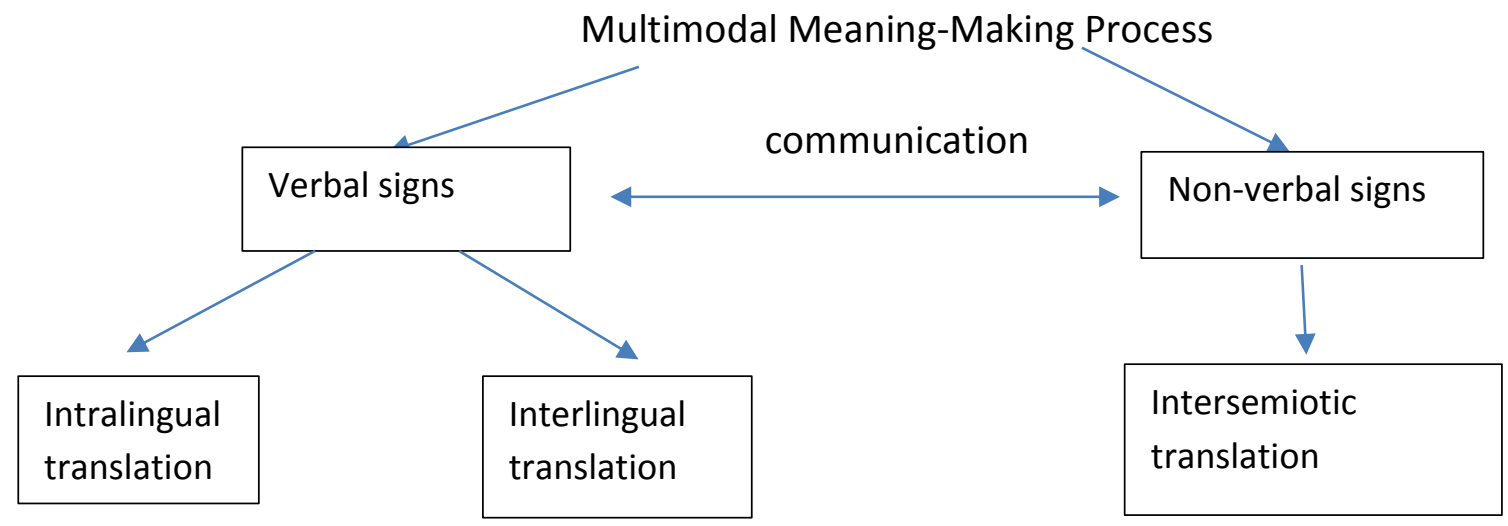

Figure 1 The Multimodal Meaning-Making Process in Translation

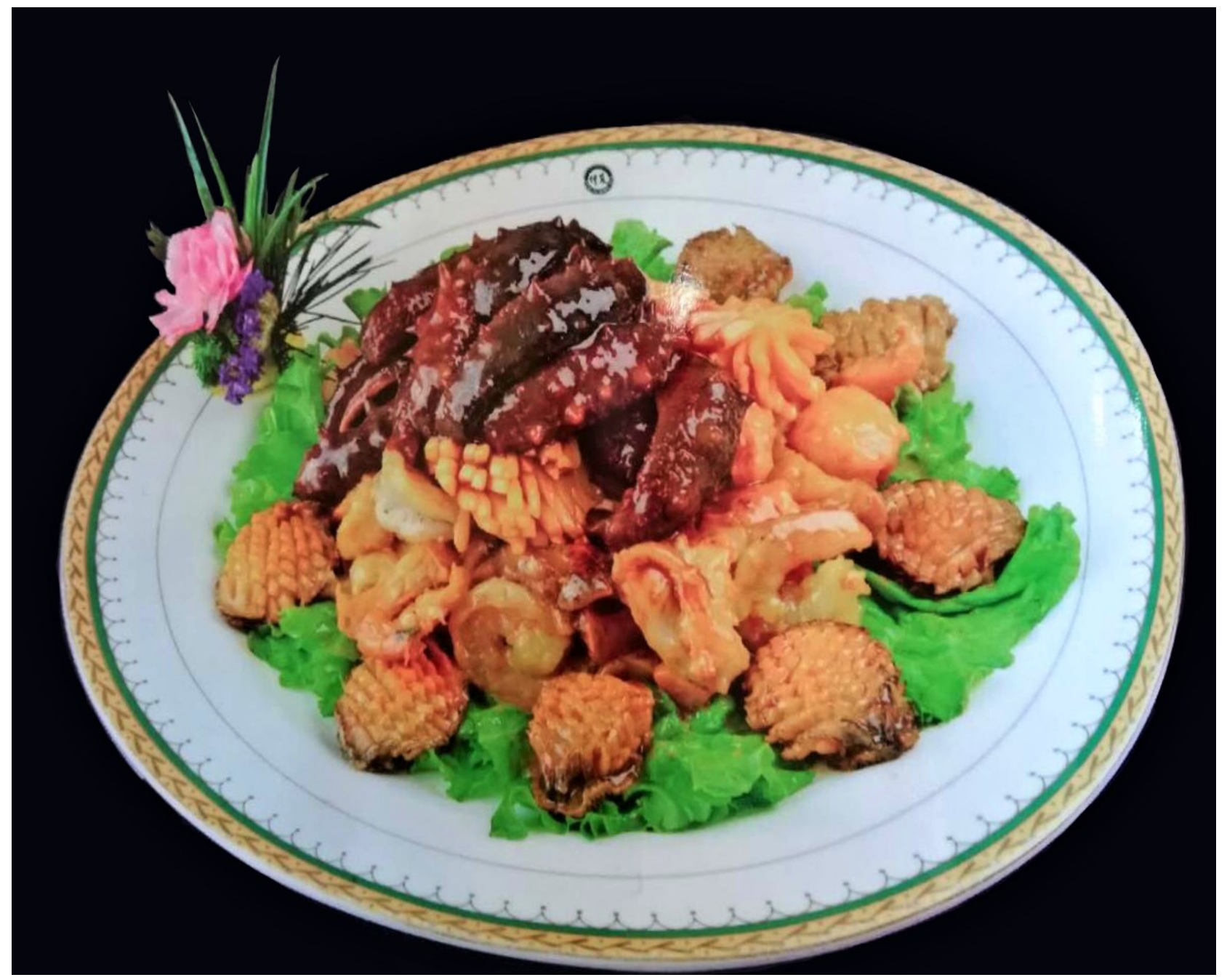

Figure 2 Quán jiā fú. 'Happy Family': Combination of shrimps, sea food, pork, beef, chicken and mixed vegetables in brown sauce 


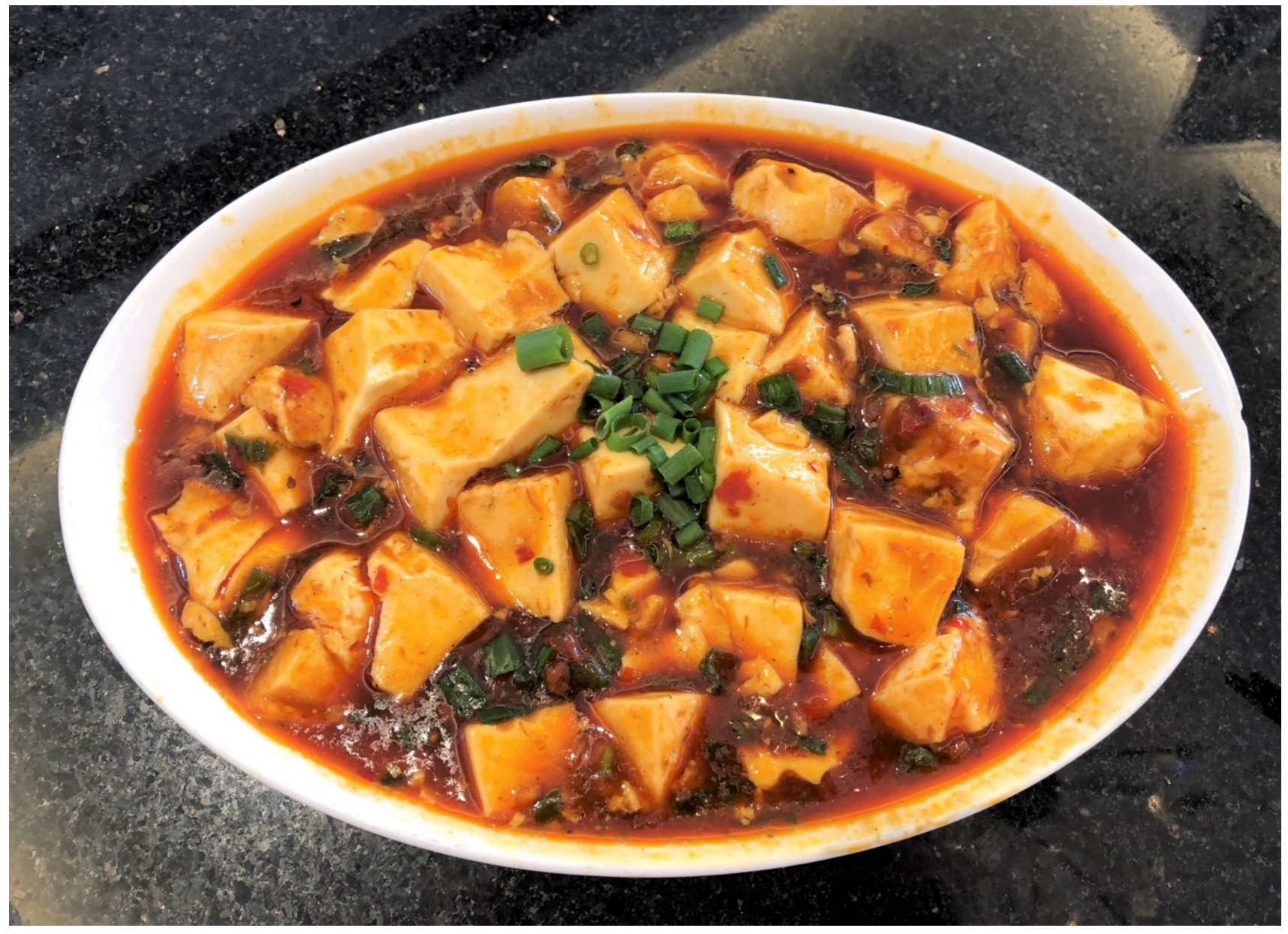

Figure 3 Quán jiā fú. 'Happy Family': Combination of shrimps, sea food, pork, beef, chicken and mixed vegetables in brown sauce 


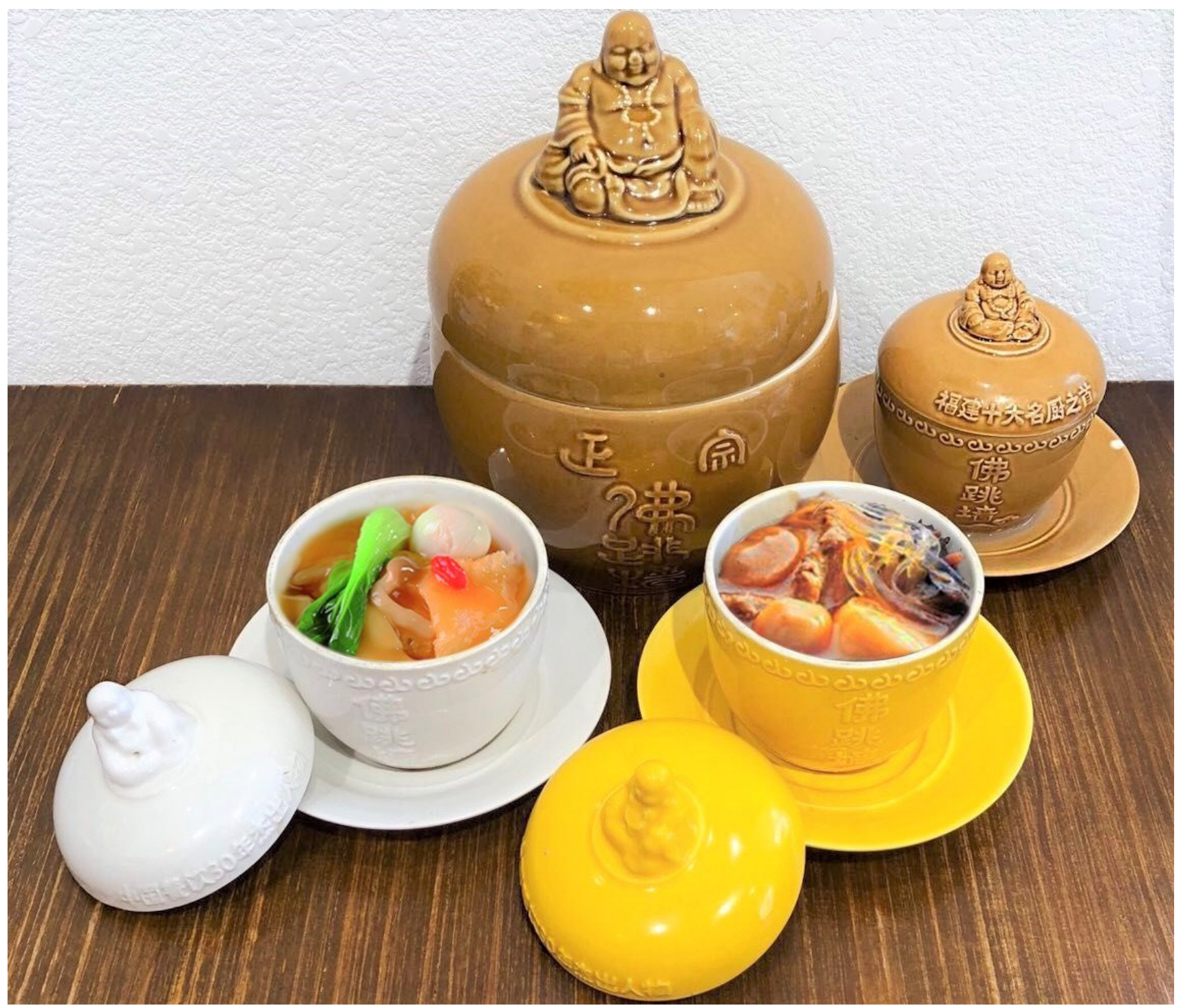

Figure 4 Fó tiào qiáng. 'Buddha Jumps Over the Wall': Steamed Abalone with Shark's Fin and Fish Maw in Broth

\footnotetext{
${ }^{1}$ http://blog.udn.com/webman/63831948

2 https://www.travel.taipei/zh-tw/featured/details/7458

3 Yin and Yang, a Chinese philosophy, suggests that opposite or contradictory forces (e.g. dark and light) are complementary, and interdependent in the natural world.

${ }^{4}$ http://www.baidu.com/

${ }^{5}$ http://www.oxfordlearnersdictionaries.com/us/

${ }^{6}$ http://hanban.edu.cn/

${ }^{7}$ My thanks go to Bingbing Leng for authorizing the use of the photo in Figure 2, and to Duoduo Li for granting me full copyright to use the photos featured in Figures 3 and 4.
} 